JSACE $4 / 9$

Urban Crime in the City of New Haven: Residential Burglaries

Received 2014/06/02 Accepted after revision 2014/09/01

\section{Urban Crime in the City of New Haven: Residential Burglaries}

\section{Irina Matijošaitiené*}

Yale University MacMillan Center, 34 Hillhouse ave., New Haven, CT 06520, USA

Kaunas University of Technology, Faculty of Civil Engineering and Architecture, Department of Architecture and Urbanism

Studentu st. 48, LT-51367 Kaunas, Lithuania

*Corresponding author: irina.matijosaitiene@yale.edu; irina.matijosaitiene@ktu.edu

$\Gamma$ Crossef http://dx.doi.org/10.5755/j01.sace.9.4.7225

The research presented in this paper is based on the space syntax theory saying that pedestrian movement strongly correlates with some topological properties of urban spaces. Since crime is closely related to the urban environment in which it happens it makes a sense to analyse urban crime through the prism of urban network. Thus, residential burglaries committed in the city of New Haven, USA, during 2009-2013 were analysed by the application of space syntax method with the combination of GIS and statistical analysis (correlation and linear regression analysis). Crime risk band analysis was applied for the calculation of burglary risk for each street segment. Research results reveal relations between mostly all the topological properties and risk band. According to the regression analysis the further a street segment with residential dwelling is from the main routes the higher burglary risk is on that segment, and also that well-connected street segments are more vulnerable to residential burglaries.

KEYWORDS: crime, GIS, residential burglary, crime risk, space syntax.

Cities by themselves are dynamic structures with street and path network, where pedestrian movement and flows create the vitality of the whole structure. Usually residential areas form the major pattern of a city. According to the previous researches (Hillier and Sahbaz 2005) city centers create higher crime rates in and around them due to the fact that they have more levels of activities and density. But does it mean we have to avoid streets and paths located in the city center in order to stay safe while moving from point A to point B? For example, if there is a well-used route with 200 people per hour and with 20 robberies per year, and there is a poorly used route with 20 people per hour and with 5 robberies per year, we would probably use the first route to our way home because the risk of a person being robbed is much less than on the second (poorly used) route. That is why in many cases it is more useful to analyze crime risk instead of crime rate, as crime rate in some segments of streets can be higher than on others but it doesn't necessarily mean that in comparison with other streets' segments this segment is more dangerous. This fact is also confirmed by 0 . Newman (1972) who states that "some commercial street corners, identified as safe, have records, showing up to three times more crimes than any other place in the immediately surrounding urban area. However, the number of pedestrians passing any point on a commercial street is over twenty times the average of surrounding streets and areas. The rate of occurrence may be higher, but the chance of occurrence per user may be lower". 


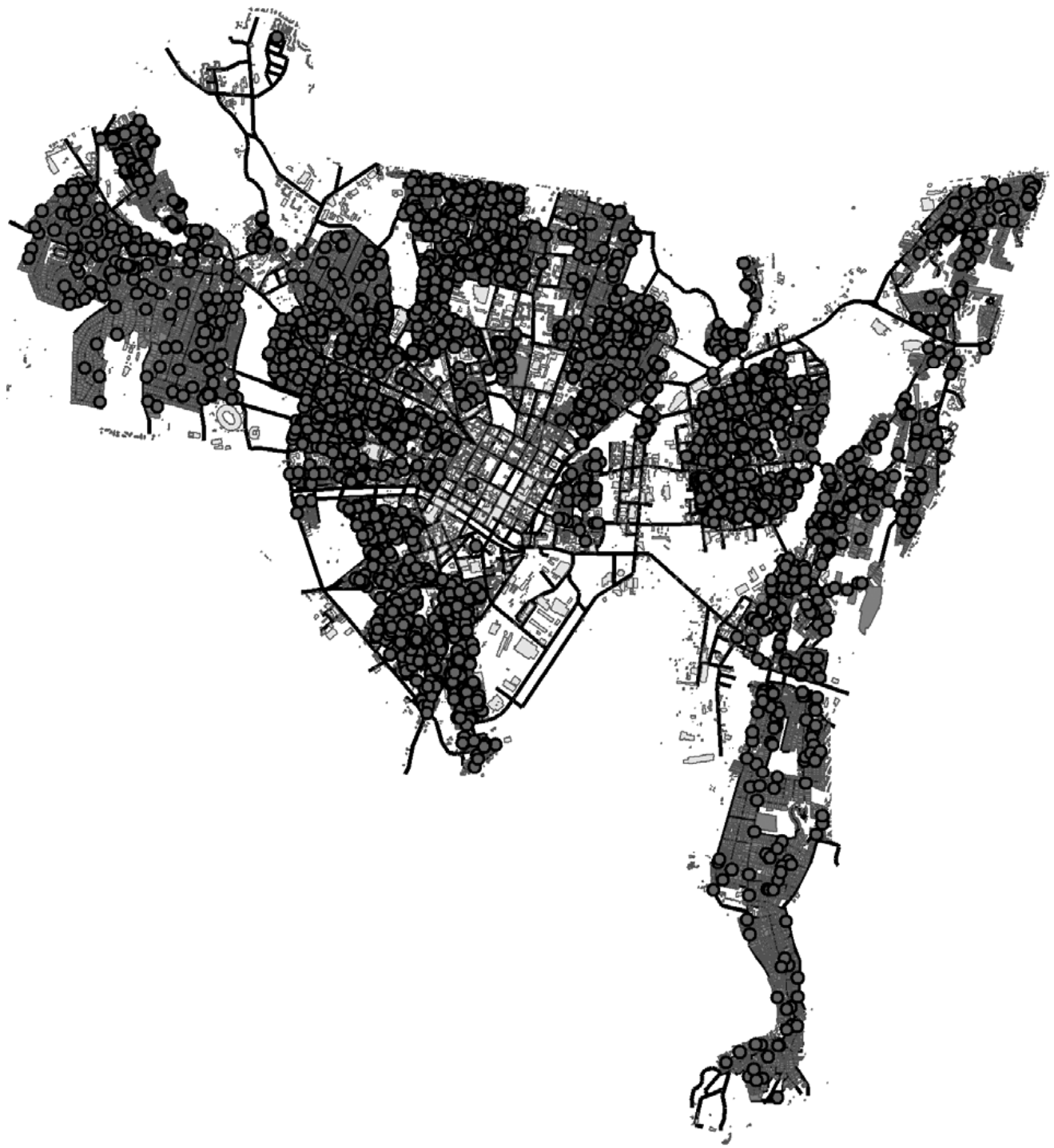

In environmental criminology it is widely established that the crime is closely related to the urban environment in which it happens (Tarkhanyan 2013). In environmental criminology greater attention is paid to the places where the crime was committed. As the experience on crime investigations shows criminals are most likely to commit a crime near their living place or on the paths which connect major activities places (shopping, leisure etc. places). For instance, as the results of M. Lopez's and A. van Nes's (van Nes and Lopez 2010) research show, "most residential burglaries took place in the most segregated and unconstituted streets that lay within a radius of $2.1 \mathrm{~km}$ from a burglar's home address". Australian institute of criminology resource says that "most burglars (77\%) travelled away from their home suburb to do their work, travelling an average of five kilometres to their target" (Ratcliffe 2003). These facts prove the hypothesis that the network of committed crimes' locations is related to a certain place. Understanding the relation between the place and the crime can help us analyse, forecast and predict the crime.

Residential burglaries in New Haven city, Connecticut, USA, are the object of this research. In this case only burglaries from one, two, three and four family residential houses were investigated, not taking into account burglaries from apartments. New Haven is the second largest city in Connecticut, with the population about 130,741 (according to Census Bureau data of July 1, 2012) and the area
Fig. 1

Distribution of residential burglaries in New Haven City. Here green coloured territories represent residential sites, and red dots represent residential burglaries exactly on the place where they were committed 
of $52.1 \mathrm{~km}^{2}$. A large part of the city is built up with Yale University buildings, laboratories, offices and dormitories. Besides Yale University, there are also some other well-known universities and colleges in New Haven. The Green is a park which is the heart of the city located in the Downtown. It is surrounded by university campus territories, offices and banks, cafes, shops, multi-storey apartment buildings, also the main bus routes and bus stops are located here. This territory can be seen in the Figure 1 as a not coloured territory in the center of the city. An interesting fact is that in 2011 New Haven was ranked as fourth most dangerous city in the United States. In this paper the research is presented seeking to identify relations between residential burglaries and topological features of urban network on a macro-level.

Space syntax method (it is a tool for topological analysis) with the combination of Geographical Information Systems (GIS) was used for the implementation of this research. Space syntax differs from other tools used for the crime analysis because it does not concentrate on the analysis of "hot spots" or particular locations where crime was committed as other tools do, but it rather analyses the whole network of streets and paths with crimes on or near them. It is proved by various researches (Hillier etc. 1993; Hillier and lida 2005; Peponis etc. 2004; Peponis etc. 1990; Turner and Penn 2002) that topologically based measures (integration, depth, control etc.) significantly correlate with pedestrian movement patterns (60-80\% correlation between moving potentials and observed movement rates, according to B. Hillier (Hillier and Sahbaz 2009).

The GIS data for the research was provided by the city of New Haven, IT Department (maps of streets and their center lines, with sites and buildings) (City ... 2014), and by the Police Department of the New Haven (all crime types committed in New Haven during the last five years in 20092013, with all crimes being geocoded) (New ... 2013). The DepthMap software is used for the calculation of the topological characteristics of urban spaces such as connectivity, global and local integration, global and local choice, global and local depth, as well as topological step depth from the main space in the city. The ArcMap software was used to combine the calculated topological characteristics with the city map and crimes.

Integration is related to "to-movement" and the accessibility of spaces, it is about deciding where to go. "Integration (closeness) says us how close each segment is to all others under different types of distance and at different scale. Integration describes how easy it is to get to one segment from all other segments. In practical terms this would mean that pedestrians would end up to such a space more often and with less effort" (Hillier and lida 2005). Global integration (with a radius $n$ ) shows how accessible an axis or a segment is from all the others, id est. how it is integrated in the scale of the whole city. More integrated spaces are used more as nearby destinations than more segregated spaces. Local integration shows how integrated the local area is in the relationship of its surroundings. In the studies of urban crime in different cities and neighbourhoods various radii for the analysis of the spatial structure on a local level have been taken into account: metric radius of 750 meters in the research of Brazilian boroughs (Reis etc. 2013), metric radius of 800 meters is used in the research of anti-social behavior crimes (drugs, dumpings, violence, graffiti, theft) in three London boroughs (Friendrich et al. 2009), topological radius of 3 in the research of burglaries and robberies in London city (Hillier and Sahbaz 2005) as well as in the research of residential burglaries and thefts from cars in two Dutch cities (van Nes and Lopez 2013) and in the research of robbery in a neighbourhood in Recife city, Brazil (Monteiro and lannicelli 2009). As B. Hillier (2007) states, for the local movement the radius of 800 meters is the best accounted. Based on $A$. van Nes (van Nes and Lopez 2013) studies of Dutch neighbourhoods ,angular analyses with a high metrical radius show how the area is connected to the location of the main routes in the city/town", and „angular analyses with a low metrical radius show the spatial potentials for the vitality of a local center inside the neighbourhood“. During the research presented in this paper various topological and angular radii were tested from 3 to 10 . 
Choice is related to the choice of path on the way to the destination or so-called "throughmovement". "Choice (betweenness) says us how much movement is likely to pass through each segment on trips between all other segments, again using different types of distance and different radii. Choice describes how likely you are to pass through the segment on trips, and so it's potential as a route, from all segments to all others" (Hillier and lida 2005). Choice also may be analysed at a global (radius $n$ ) and local (2, 3 etc. radii) levels.

Connectivity is a local characteristic which lets us know about the direct connection of spaces. Connectivity is defined as the number of nodes that connect directly to a given node (Raford and Ragland 2004).

Depth measures the social cultural integrity of the inner spaces of the downtown. Depth defines the number of steps from any node to any other node (Raford and Ragland, 2004).

For the spatial analysis of New Haven and for the calculation of the topological measure segment analysis was performed and the segmental map of the city was created. According to B. Hillier (Hiller and lida 2005) segment analysis has the advantage over axial line analysis in being more detailed and producing better correlation with movement analysis. Segment is the shortest path which uses the least number of streets (actually the least number of "interjunction" stretches of street) to get to your destination. In the angular analysis the main idea is to find the shortest path which is the one that minimises the angle between you and your destination (Turner 2008). After the segment map was build it was associated with crime map.

Residential burglaries were analyzed considering burglary rate and burglary risk, the latter is called "primary risk band analysis" by B. Hillier and O. Sahbaz (2005). Burglary rate was calculated by dividing the total number of burglaries on a segment by the total number of targets (in this case it is the number of residential houses) on this segment. This measure indicates the crime rate for the specific segment, and on the basis of this calculation we can identify more and less vulnerable to burglary segments. Crime rates were used for the analysis of residential burglaries and robberies in some Brazilian boroughs by A. T. Reis and his colleagues (Resi et al. 2013). However, according to B. Hillier and O. Sahbaz (2005) representing crime rate as an information about crime on segments will result in a wrong illusion that segments with high numbers of dwellings have lower crime rates. Though, it is not necessarily may correspond with the real situation. Therefore, to escape this problem B. Hillier and O. Sahbaz (2005) suggest to aggregate „all segments with a given number of residential units, or within a certain band of residential units, and calculating a burglary rate is for the whole group as the total number of burglaries over the total number of targets for that group“, and they use a term „primary risk band analysis“ to name this process of aggregating the segments. Differently from crime rate, crime risk for the bands is calculated in this way: 1. Segments with an equal number of residential units are selected and grouped into bands, 2 . Within these bands (for each of made bands) the total number of crimes in segments is divided by the total number of residential units in these segments. Crime risk band represents calculation results for a specific band (for example, a band of street segments with five houses, or for a street segment with housing density of three houses). Crime risk band analysis was used by B. Hillier and O. Sahbaz (2005) in their research of burglaries in London city, by A. van Nes and M. Lopez (2010) in their research of burglaries and thefts from cars in Dutch cities and neighbourhoods.

According to the above described methodology burglary rate and risk band were calculated for all segments. For the identification of the most important (having in mind mostly used) space in the city choice measures with calculated various angular and topological radii (radii from 3 to 10) were compared. It was identified that Elm street segment which lays between Broadway and York streets is the most important and mostly chosen route. This street segment is in the Downtown of New Haven connecting many important routes within and outside the city, with boutiques, bars,

\section{Results}


Fig. 2

Distribution of burglary rates

Fig. 3

Residential burglary rates of street segments

Fig. 4

Distribution of burglary risk band
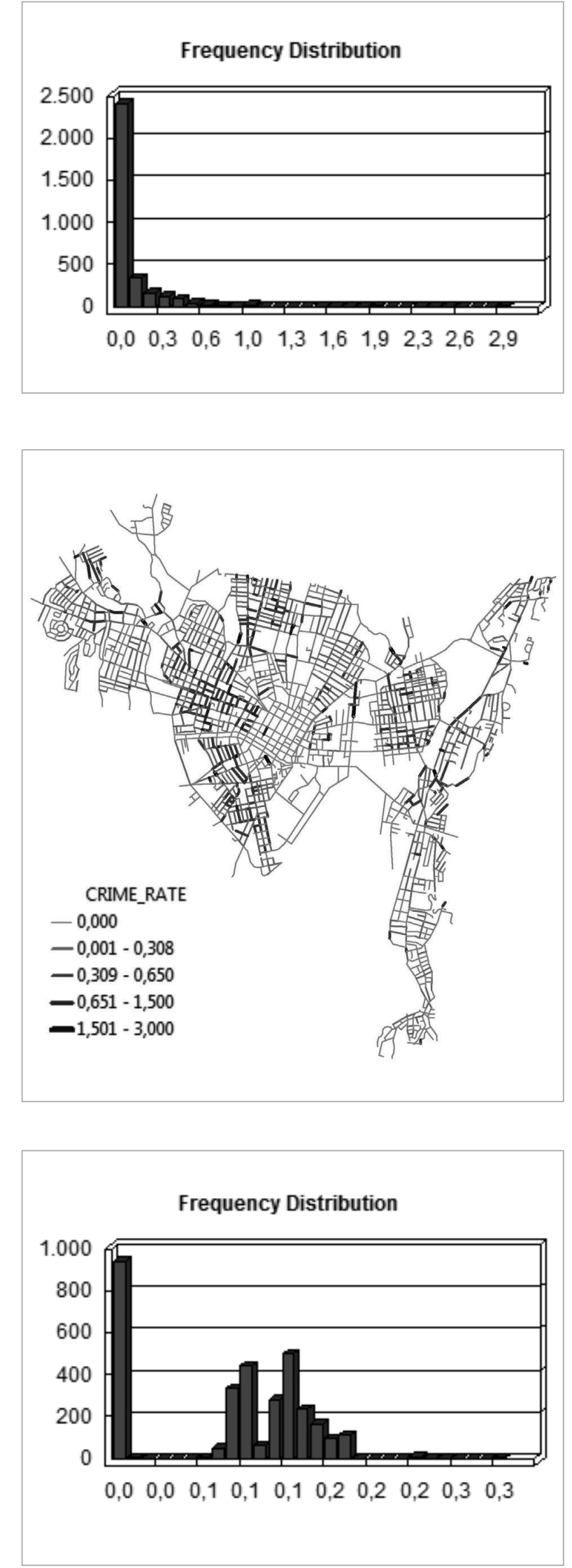

apartments above them, on both sides of the segment, also a grocery shop in a distance of a couple of steps on the next street segment, that definitely attract people. In this case, topological depth from this segment of Elm street to all other segments was calculated.

The calculated crime rate for each segment differs from 0 to 3 (Fig. 2), where $68.1 \%$ of segments are with a 0 crime rate, $22.25 \%$ of segments with the crime rate $0.001-0.308$, $7.65 \%$ of segments with the crime rate $0.309-0.650,1.71 \%$ of segments with the crime rate $0.651-1.500,0.28 \%$ of segments with the crime rate 1.501-3.000.

All values of the calculated crime rates were divided into five groups (according to the natural breaks (Jenks) with an exclusion of 0 values), and the map of less and more burgled street segments was drawn (Fig. 3).

According to the method developed by B. Hillier and O. Sahbaz (2005) 54 bands of street segments were formed. The total number of segments is 3214 . The calculated values of burglary risk band and its distribution is strongly different from calculated burglary rates and their distribution (Fig. 4). Calculated crime risk differs from 0 to 0.305 , where $29.28 \%$ of segments are with a 0 crime risk, $0.19 \%$ of segments are with the crime risk 0.013-0.077, $45.36 \%$ of segments are with the crime risk $0.078-0.136,18.61 \%$ of segments are with the crime risk 0.137-0.156, $6.57 \%$ of segments are with the crime risk 0.157-0.305. Here we see that the most of segments (69.01\%) have crime risk which is higher than the average value of 0.089 , and $54.01 \%$ of segments have higher crime risk values than the median value 0.101 . According to the above described facts it can be concluded that more than half of the street segments in New Haven are quite vulnerable to residential 
burglary because their burglary risks are higher than the average and median values.

The map of more and less vulnerable to residential burglary street segments in New Haven was created (according to the calculated crime risk band values of each segment) (Fig. 5).

According to the crime risk band analysis the most vulnerable to residential burglary are street segments with 41 (with crime risk 0.305), 44 (with crime risk 0.25) and 32 (with crime risk 0.241 ) residential dwellings. Though, it does not mean that high crime risk is statistically related to the above mentioned numbers of segments. Moreover, figure 5 clearly demonstrates a strong relation between calculated residential burglary rate and the number of residential dwellings, in contrast to burglary risk band (Fig. 6) which is not related to the number of residential dwellings on segments. That means, that further analysis of crime rate may lead to wrong interpretation of the results, because it shows that the less residential dwellings are on a segment the higher burglary rate is on that segment. Therefore, crime risk band values are used for the statistical analysis.

All calculated topological measures of the New Haven City as well as crime risk band were used for the statistical analysis. Pearson correlation analysis demonstrates relations between mostly all the topological properties and risk band. Smaller correlations are observed for the depth, choice and integration with topological radii in comparison with the angular radii. Linear regression analysis discovered that there was a significant relation between burglary risk band and local depth at a topological radius $3\left(R^{2}=0.1\right.$, $p=0.000<a=0.05$ ), that means that the further a street segment with

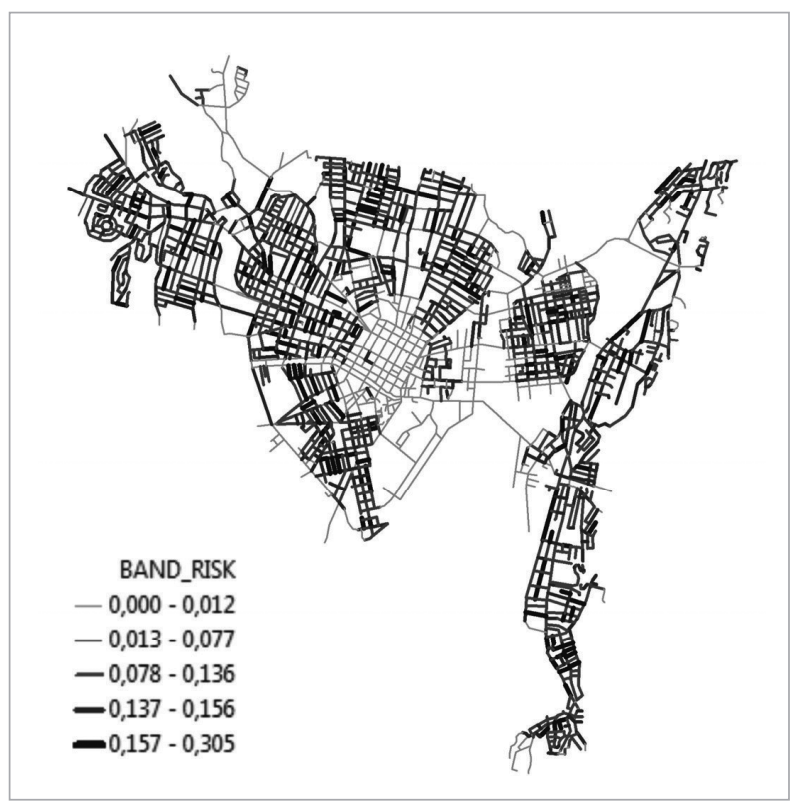

Fig. 5

Street segments vulnerability to residential burglary based on crime risk bank analysis

Fig. 6

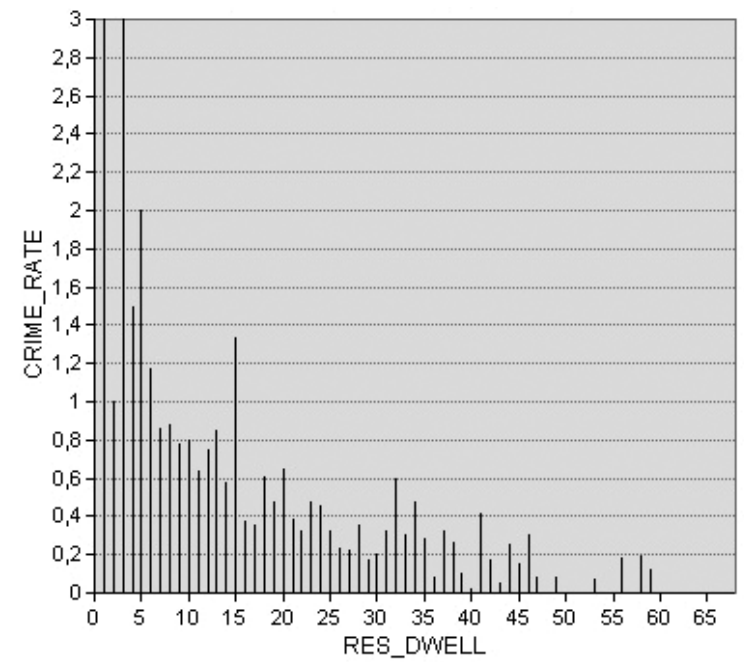

Relation between burglary rate and the number of residential dwelling on a segment (picture above), and relation between burglary risk band and the number of residential dwelling on a segment (picture below)

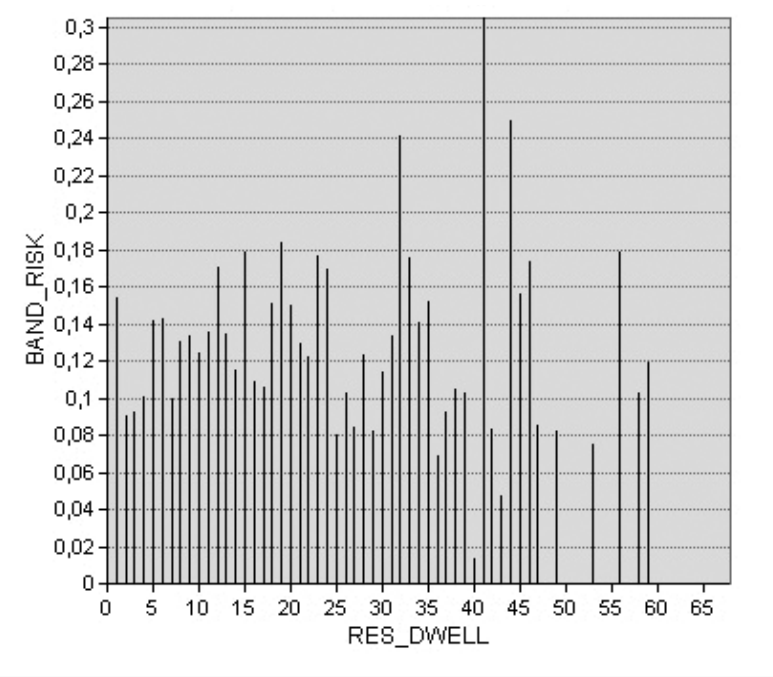


Fig. 7

Depth R3 step map with locations of residential burglaries. Here cold colours (dark blue, blue and green) mean deep street segments, warm colours (red, orange, yellow) mean shallow street segments. Black dots are residential burglaries

Fig. 8

Connectivity map with locations of residential burglaries. Here cold colours (dark blue $=1$, blue $=2$ and green $=3$ ) mean weakly-connected street segments, warm colours (red $=6$, orange $=5$, yellow=4) mean well-connected street segments. Black dots are residential burglaries

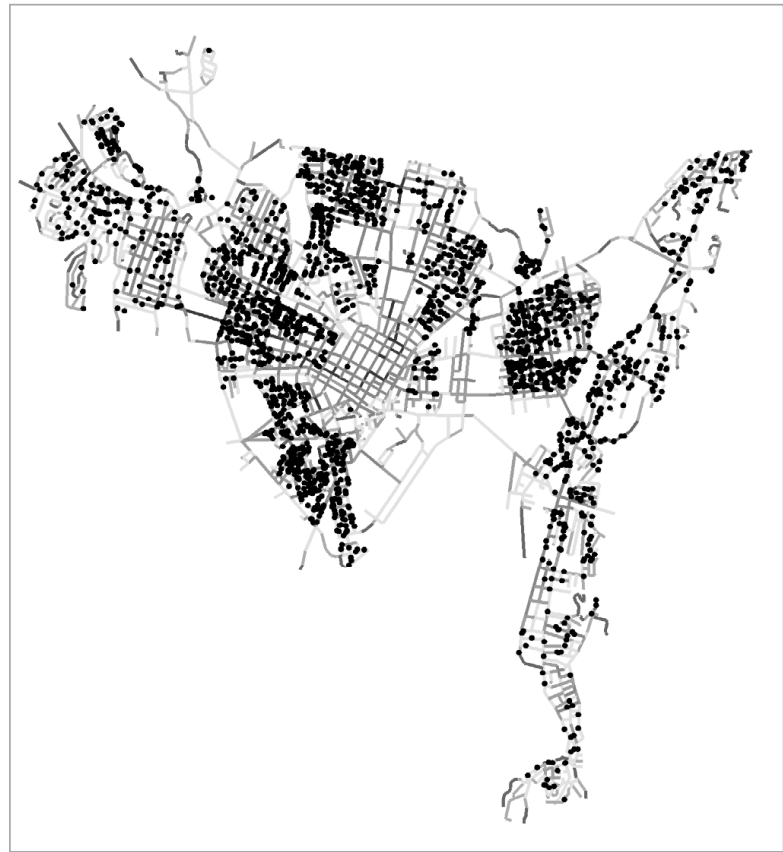

residential dwelling is from the main routes the higher burglary risk is on that segment. The visual analysis of the depth R3 step map layered by the locations of residential burglaries (Fig. 7) makes it obvious that the major part of the burglaries are located on deeper street segments (blue and dark blue coloured). That proves the fact that at the local level deeper street segments generate higher crime risk for residential dwellings.

Also there is a significant relation between burglary risk band and connectivity $\left(R^{2}=0.3, p=0.000<a=0.05\right)$. After comparing these results with the connectivity map layered by the locations of residential burglaries (Fig. 8) it becomes obvious that more vulnerable to residential burglaries street segments are those that are well connected. For instance, if a street segment connects by its ends with 6 or 5 or 4 other segments it will definitely be more attractive for a burglar, than a street segment that connects with 1 or 2 other segments. Here also another evidence can be applied: wellconnected streets might attract more pedestrian movements because they connect to more other segments. Together with regular pedestrians they may attract burglars as well.

There are also significant though very weak positive relations between residential burglary risk band and segment length, significant though very weak negative relations between residential burglary risk band depth R4.00 (angular), depth R10

(topological), and global choice. That could mean that the longer a street segment is the higher burglary risk is on it. And the less a segment is chosen to pass on the way to other segments ("through-movement") the higher burglary risk is on that segment. According to the regression model and to the coefficients table, it can be stated with an assurance of $95 \%$ that with the increase of street segment connectivity by 1 conditional unit the burglary risk will increase by 0.1 0.5 units, and with the increase of street segment depth R3 step by 1 conditional unit the burglary risk will increase by 0.1 . Though, a rather large constant 1.05 does not explain the dispersion of all the variables that is why the remaining part of the factors determining the burglary risk 
remains unknown for us. That is to say, that street segments that are further from the main routes, less connected, longer and less used on the way to the destination are more vulnerable to residential burglary.

This research provides new insights into how crime may be analysed through the topological properties of urban spaces. The case of New Haven city demonstrates that deep at the local scale urban spaces and poorly connected spaces generate higher risks for residential dwellings located on these spaces to be burgled. Comparing these results with the ones from the research of Dutch cities Alkmaar and Gouda (van Nes and Lopez 2010) we see that in Dutch cities there are correlations between burglary risk and topological depth, risk and constitutedness, risk and local integration. In the analysis of New Haven constitutedness was not taken into account due to not enough time for it (it is supposed to be a subject for the further research). Pearson correlation in the case of New Haven demonstrated relations between local (with angular radii) and global integration and risk band. Also in both Dutch cities and New Haven mostly all topological properties correlate with risk band. In the research of burglaries in London city (Hillier and Sahbaz 2005) they discovered that streets segments with 1-2 connected segments (low connectivity value) have the lowest average burglary rates. For B. Hillier and O. Sahbaz this finding was unexpected and shocking. They commented about that: "it is striking that the greater connectivity in the street pattern itself is associated with less, rather than more burglary" (Hillier and Sahbaz 2005). In the research of New Haven it is opposite: street segments with higher connectivity values are more vulnerable to burglaries, what is likely to be the result that B. Hillier and 0 . Sahbaz were suspected to get in their research. In their research of London more burglaries were committed on longer street segments, the same is observed in New Haven. This fact about the positive relation between segment length and burglary risk also coordinates with the fact about positive correlation between connectivity and risk, because according to many researchers street length is strongly related to connectivity. In London burglaries more occur on locally and globally (R15) integrated segments. Pearson correlation in New Haven case also shows relations between local and global integration and burglary risk.

Due to a large constant 1.05 in the regression model that expresses independent variables influencing burglary risk, there is a need to extend the research on a micro-level, taking into account such factors as building centered density, dwelling and street types, constitutedness, land use, street form, intervisibility, step depth from house entrance to the street segment, greenery, lighting and various factors of surrounding environment. That is the aim of future research.

Analysis and comparison of the calculated burglary rates and burglary risks led us to the decision to use burglary risk for the macro-scale analysis because burglary rates show nothing more except increase the rates with the decrease of the number of targets, id est. the number of residential dwellings.

Pearson correlation analysis demonstrates relations between mostly all the topological properties and risk band. Smaller correlations are observed for the depth, choice and integration with topological radii in comparison with the angular radii.

Linear regression analysis discovered that there was a significant relation between burglary risk band and local depth at a topological radius $3\left(R^{2}=0.1, p=0.000<a=0.05\right)$, that means that the further a street segment with residential dwelling is from the main routes the higher burglary risk is on that segment. Also there is a significant relation between burglary risk band and connectivity $\left(\mathrm{R}^{2}=0.3, \mathrm{p}=0.000<\mathrm{a}=0.05\right)$. That means that more vulnerable to residential burglaries street segments are those that are well connected. There are also significant though very weak positive relations between residential burglary risk band and segment length, significant though very weak negative relations between residential burglary risk band depth R4.00 (angular), depth R10 (topological), and global choice.

\section{Discussion}

\section{Conclusions}


The results of this research are very similar to the results that were got in Dutch cities and London city. Though, concerning a high constant in the regression model the research need to be conducted at the micro-level in order to identify more factors that influence burglary risk on the street segments of New Haven.

Acknowledgment
The author is grateful to J.P.Kazickas fund which supported with fellowship for this postdoctoral research, the Baltic Studies at the MacMillan Center at Yale University for organizing the appointment as a J.P.Kazickas research fellow, to the IT Department of the city of New Haven for providing the GIS data, to the Police Department of the New Haven for providing the geocoded data about crime, and to Stacey Maples for the support with ArcMap.

\section{References}

City of New Haven, IT Department. 2014. GIS data.

Friendrich E., Hiller B., Chiaradia A. 2009. Anti-social behavior and urban configuration. In: Proceedings of the 7th International Space Syntax Symposium, Stockholm, Sweden, 034:1-034:16.

Hillier B., Sahbaz 0. 2009. Crime and urban design: an evidence-based approach. In: Coper R., Evans G., Boyko C. Designing sustainable cities. Singapore, Blackwell Publishing, 163-186.

Hillier B. 2007. Using DepthMap for urban analysis: a simple guide on what to do once you have an analysable map in the system. MSc Advanced Architectural Studies, 2007-8. UCL, London. Available at: https://www.jiscmail.ac.uk (accessed 14 April 2014).

Hillier B., Sahbaz 0. 2005. High resolution analysis of crime patterns in urban street networks: an initial statistical sketch from an ongoing study of a London borough. In: Proceedings of the Fifth International Space Syntax Symposium, Delft, Netherlands, 451-478. Available at: http://spacesyntax.tudelft. $\mathrm{nl} /$ media/Long\%20papers\%20l/hilliersahbaz.pdf (accessed 14 April 2014).

Hillier B., lida S. 2005. Network and psychological effects in urban movement. In Proceedings of Spatial Information Theory: International Conference, New York, USA, 475-490.

Hillier B., Penn A., Hanson J., Grajewski T., Xu J. 1993. Natural movement: or, configuration and attraction in urban pedestrian movement. Environment and planning B: Environment and design, 20(1), 29-66.

Monteiro C., Iannicelli C.P. 2009. Spatial profiles of urban segments: the role of morphology in a context of social inequality. In: Proceedings of the Seventh International Space Syntax Symposium, Stockholm, Sweden. 2009, 080:1-080:11.
New Haven Police Department. 2013. GIS data about crime.

Newman 0. 1972. Defensible Space: Crime Prevention through Urban Design. New York, Macmillan.

Peponis J., Dalton R.C, Wineman J., Dalton N. 2004. Measuring the effects of layouts upon visitors' spatial behaviors in open plan exhibition settings. Environment and planning B: Environment and design, 31(3), 453-473.

Peponis J., Zimring C., Choi Y.K. 1990. Finding the building in wayfinding. Environment and behavior, 22(5), 555-590. http://dx.doi. org/10.1177/0013916590225001

Raford N., Ragland D.R. 2004. Space Syntax: An Innovative Pedestrian Volume Modeling Tool for Pedestrian Safety. Transportation Research Record, 2004, 1878, 66-74. Available at: http://dx.doi. org/10.3141/1878-09 (accessed 15 July 2012).

Ratcliffe J.H. Suburb boundaries and residential burglars. Australian institute of criminology, 2003. Available at: http://www.aic.gov.au/media_library/ publications/tandi/ti246.pdf (accessed 14 April 2014).

Reis. A.T., Dutra M., Zago G. 2013. Effects of some segments features on residential crime in two boroughs. In: Proceedings of the Ninth International Space Syntax Symposium, Seoul, Korea. 2013, 112:1-112:12.

Tarkhanyan L. 2013. Drug crime and urban mosaic: the locational choices of drug crime in relation to high streets, bars, schools and hospitals. In: Proceedings of the Ninth International Space Syntax Symposium, Seoul, Korea. 2013, 101:1-101:13.

Turner A. 2008. Getting serious with Depthmap. Segment analysis and scripting. Available at: https://www.bartlett.ucl.ac.uk/graduate/research/ space/research/ucl-depthmap/documents/ advanceddepthmap.pdf (accessed 14 April 2014). 
Turner A., Penn A. 2002. Encoding natural movement as an agent-based system: an investigation into human pedestrian behavior in the bult environment. Environment and planning B: Environment and design, 29, 473-490.

van Nes A., Lopez M. 2013. Spatial-socio classification of deprived neighbourhoods in the Netherlands: Strategies for neighbourhood revitalisation. In: Proceedings of the Ninth International Space Syntax Symposium, Seoul, Korea. 2013, 122:1-122:14.

van Nes A., Lopez M.J.J. 2010. Macro and micro scale spatial variables and the distribution of residential burglaries and theft from cars. Journal of Space Syntax, 2010, 1(2), 296-314.

\section{IRINA MATIJOŠAITIENÉ}

\section{Assoc. Professor}

Yale University, MacMillan Center, Visiting Scholar, and Kaunas University of Technology, Faculty of Civil Engineering and Architecture, Department of Architecture and Land Management

\section{Main research area}

Main research area: urban and road landscape, space syntax, Kansei engineering, hedonomics, ergonomics, statistics

\section{Address}

34 Hillhouse ave., New Haven, CT 06520, USA, and Studentu st. 48, LT-51367 Kaunas, Lithuania

Tel.: +1 347515 5449, +370 37300456

E-mail: irivarl@yahoo.com,

irina.matijosaitiene@ktu.lt,

irina.matijosaitiene@yale.edu 